\title{
Comparative Study of Low Pressure versus Standard Pressure Carbon Dioxide Pneumoperitoneum in Reducing Shoulder Tip Pain Post Laparoscopic Cholecystectomy
}

\author{
Thapa $\mathrm{P}^{1}$, Thapa $\mathrm{D}^{1}$, Sharma $\mathrm{A}^{1}$
}

\begin{abstract}
Introduction: Laparoscopic cholecystectomy is the gold standard treatment for cholelithiasis. Postoperative shoulder tip pain is common complaint. Evidences suggest that using low pressure pneumoperitoneum $(8-10 \mathrm{mmHg})$ during the procedure rather than standard pressure $(12-14 \mathrm{mmHg})$ decreases the incidence and severity of shoulder tip pain without compromising working space. Aims: The aim of this study was to evaluate the impact of low pressure and standard pressure pneumoperitoneum on shoulder tip pain post laparoscopic cholecystectomy. Methods: A prospective hospital based study conducted at Nepalgunj Medical College, Kohalpur from January 2019 to December 2020. Hundred patients were enrolled, fifty each in "low pressure carbondioxide pneumoperitoneum" and "standard pressure carbondioxide pneumoperitoneum" groups, who underwent laparoscopic cholecystectomy. The two groups were compared in terms of incidence and severity of shoulder tip pain, surgeon's satisfaction score, top-up analgesia requirement, procedural time, conversion to standard pressure, intraoperative complications and length of hospital stay. Results: There were 45 (90\%) females and five (10\%) males in low pressure group and 44 (88\%) females and six (12\%) males in standard pressure group. Fourteen (28\%) patients in low pressure and 32 (64\%) patients in standard pressure group had shoulder tip pain $(p=0.001)$. The severity of shoulder tip pain was less in low pressure group and was significant at eight hours $(p=0.006)$ and 12 hours ( $p=0.008)$. Top-up analgesia was required more in standard pressure group. There were no intraoperative complications but only one conversion to standard pressure. Surgeon's satisfaction score, conversion to open cholecystectomy and procedural time were comparable in both groups with shorter hospital stay in low pressure group. Conclusion: Low pressure carbondioxide pneumoperitoneum is safe and effective strategy in reducing incidence and severity of shoulder tip pain after laparoscopic cholecystectomy.
\end{abstract}

Keywords: Laparoscopic cholecystectomy, Low pressure carbondioxide pneumoperitoneum, Shoulder tip pain, Standard pressure carbondioxide pneumoperitoneum, Surgeons' satisfaction.

Authors:

1. Dr. Pradip Thapa

2. Dr. Divas Thapa

3. Dr. Anup Sharma

${ }^{1}$ Department of Surgery, Nepalgunj Medical College and Teaching Hospital, Kohalpur, Banke

\section{Address for Correspondence:}

Dr. Pradip Thapa

Department of Surgery

Nepalgunj Medical College and Teaching Hospital

Kohalpur, Banke

Email: pradip.ananta12@gmail.com

\section{INTRODUCTION}

Laparoscopic cholecystectomy (LC) has become the gold standard treatment for cholelithiasis. ${ }^{1}$ Carbondioxide $\left(\mathrm{CO}_{2}\right)$ pneumoperitoneum is a primary step for all laparoscopic procedures. Intra-abdominal pressure of $12-15 \mathrm{mmHg}$ is accepted as standard pressure for adequate working space and organ visualization. ${ }^{2}$ This pressure has been associated with adverse cardiac, pulmonary and renal effects and with also increased incidence of shoulder tip pain (STP). ${ }^{3,4}$ Twenty to $80 \%$ patients following LC suffer from STP. ${ }^{5}$ Peritoneal stretching and diaphragmatic irritation by $\mathrm{CO}_{2}$ and irritative carbonic acid formed after mixing with peritoneal fluids lead to STP. ${ }^{5}$ Many randomized controlled trials (RCTs) have shown the promising results of different maneuvers like low pressure $\mathrm{CO}_{2}$ pneumoperitoneum (LPCP) at the range of $8-10 \mathrm{mmHg}$, low insufflation flow, use of drains, abdominal wall lift (AWL), active gas aspiration, low insufflation flow, $\mathrm{N}_{2} \mathrm{O}$ pneumoperitoneum, intraperitoneal instillation of bupivacaine, pulmonary recruitment maneuver (PRM) and intraperitoneal normal saline infusion (INSI)in significant reduction of incidence and severity of STP after LC. However the LPCP is the best documented method and is also superior to SPCP in terms of better intraoperative hemodynamics, lower postoperative abdominal pain and decreased need of top-up analgesia and shorter length of hospital stay (LHS). ${ }^{6-9}$ The primary objective of this study was to compare the impact of LPCP and SPCP on incidence and severity of STP. The secondary objectives were to compare surgeon's satisfaction score, top-up analgesia requirement, procedural time, conversion to high pressure, intraoperative complications and LHS.

\section{METHODS}

This was a prospective hospital based study carried out in the department of surgery, Nepalgunj Medical College and 
Teaching Hospital, Kohalpur for the period of one year from 2019 January to 2020 December. A total of 100 patients aged between 18 and 60 years having symptomatic gallstone disease admitted for elective laparoscopic cholecystectomy were enrolled in the study. Patients with $\mathrm{BMI}>30 \mathrm{~kg} / \mathrm{m}^{2}$, ASA grade III and above, history of complicated gallstone diseases like acute cholecystitis, with history of cholangitis, pancreatitis, Endoscopic Retrograde Cholangiopancreatography (ERCP) and stenting, significant co-morbidities like coronary artery disease, asthma, chronic obstructive pulmonary disease (COPD), previous malignancy or history of multiple abdominal surgery, known shoulder disease, chronic analgesic use and patients requiring concomitant procedures were excluded. Patient were allocated in two groups 50 each, by simple random technique through chit box method into LPCP $(8-10 \mathrm{mmHg})$ and SPCP (12 $-14 \mathrm{mmHg}$ ). All the patients were educated preoperatively regarding Visual Analogue Scale (VAS) on a $10 \mathrm{~cm}$ long horizontal scale ( 0 being no pain and 10 being extreme pain). ${ }^{10}$ Under general anesthesia pneumoperitoneum was created with $\mathrm{CO}_{2}$ insufflations using the veress needle technique, until abdominal pressure of $14 \mathrm{mmHg}$ was reached. After all four ports were inserted, pressure was subsequently reduced to 8-10 $\mathrm{mmHg}$ in LPCP group while in SPCP group 12-14 $\mathrm{mmHg}$ pressure was maintained throughout the procedure. If in any patient laparoscopy was converted to open cholecystectomy those were also excluded. Any patient in low pressure group requiring conversion to standard pressure for the completion of laparoscopy was included subsequently into standard pressure group. At the end of the procedure, the $\mathrm{CO}_{2}$ was allowed to escape completely by opening the ports. All the intraoperative details were noted and immediately after surgery, surgeon's satisfaction score to pneumoperitoneum regarding exposure and instrument maneuverability during the procedure was measured on a Likert scale of 1 to $5(1=$ Very difficult/very poor and $5=$ Easy/Good). ${ }^{11}$ Postoperatively the patients were admitted at least for 24 hours. During this postoperative period, intravenous analgesic (Injection Ketorolac $30 \mathrm{mg}$ ) was given eight hourly. Top-up analgesia (Injection Tramadol 50 $\mathrm{mg}$ ) was given on demand. Patients were discharged on oral analgesics, Tablet Ketorolac $10 \mathrm{mg}$ eight hourly for three days and Tablet Tamadol Hydrochloride $50 \mathrm{mg}$ on demand. Both the patient and the non-operating surgeon who assessed the pain postoperatively were blinded for the pnumoperitoneum pressure. The degree of STP was assessed by means of visual analogue scale at four, eight, 12, 24 hours postoperatively and during follow up on seventh postoperative day (POD). The incidence and severity of STP as primary outcome measure was compared between two groups and secondary outcome measures like surgeon's satisfaction score, top-up analgesia requirement, intraoperative complications, conversion to standard pressure, procedural time, and LHS were compared between two groups. Ethical clearance was taken from the institutional research committee.

Statistical analysis was done using IBM Statistical Package for Social Science (SPSS) version 25. Categorical data was compared by Chi-Square test. Independent t-test was used to compare means. A p value of $<0.05$ was considered as statistically significant.

\section{RESULTS}

Over a period of one year, 100 patients were studied. There were $45(90 \%)$ females and five $(10 \%)$ males in LPCP group and $44(88 \%)$ females and six (12\%) males in SPCP group. The demographic and clinical parameters were comparable in both groups. There were no intraoperative complications like bile duct injury, bowel and liver injury or bleeding in both groups. There was one conversion of LPCP to SPCP because of decreased working space and operative difficulty and was included in SPCP group but none of the patients in SPCP group required increased pressure beyond $14 \mathrm{mmHg}$. Laparoscopy was converted to open cholecystectomy due to dense adhesions around Calot's triangle in four cases, two in each group and illdefined biliary anatomy in one case in SPCP group but this was statistically insignificant $(p=0.64)$. The surgeon's satisfaction score on Likert scale was higher in SPCP group $(4.82 \pm 0.38)$ than in LPCP group $(4.66 \pm 065)$ but was insignificant $(p=0.14)$. LHS was higher in SPCP group $(1.20 \pm 0.53)$ than in LPCP group $(1.02 \pm 0.14)$ and was statistically significant $(p=0.02)$ (Table I).

\begin{tabular}{|lccc|}
\hline Parameters & $\operatorname{LPCP}(n=50)$ & $\mathrm{SPCP}(\mathrm{n}=50)$ & $\mathrm{p}$ value \\
\hline Mean Age (years) & $38.20 \pm 11.44$ & $37.10 \pm 11.69$ & 0.63 \\
\hline Female: Male ratio & $45: 5$ & $44: 6$ & 0.74 \\
\hline $\mathrm{BMI}\left(\mathrm{kg} / \mathrm{m}^{2}\right)$ & $22.70 \pm 2.90$ & $22.26 \pm 2.86$ & 0.44 \\
\hline Gall Bladder perforation & 5 & 4 & 0.72 \\
\hline Drain placement & 3 & 3 & 1.00 \\
\hline Procedural time $(\mathrm{min})$ & $42.90 \pm 19.49$ & $40.98 \pm 19.35$ & 0.62 \\
\hline Conversion to SPCP & 1 & - & 0.31 \\
\hline $\begin{array}{l}\text { Conversion to } \\
\text { cholecystectomy }\end{array}$ & 2 & 3 & 0.64 \\
\hline $\begin{array}{l}\text { Surgeon's satisfaction score } \\
\text { Length of hospital stay }\end{array}$ & $4.66 \pm 065$ & $4.82 \pm 0.38$ & 0.14 \\
\hline
\end{tabular}

Table I:Demographic and clinical characteristics of patients; BMI: Body Mass Index; LPCP: Low Pressure $\mathrm{CO}_{2}$ Pneumoperitoneum; SPCP: Standard Pressure $\mathrm{CO}_{2}$ Pneumoperitoneum

Fourteen (28\%) patients in LPCP group and $32(64 \%)$ patients in SPCP had STP during hospital stay $(p=0.001)$. None of the patients in each group complained of STP at seven days follow up. Although more patients experienced it at four, eight, 12 and 24 hours intervals in SPCP group, it was statistically significant at only eight hours $(p=0.004)$ and at 12 hours $(p=0.007)$ only (Figure 1).

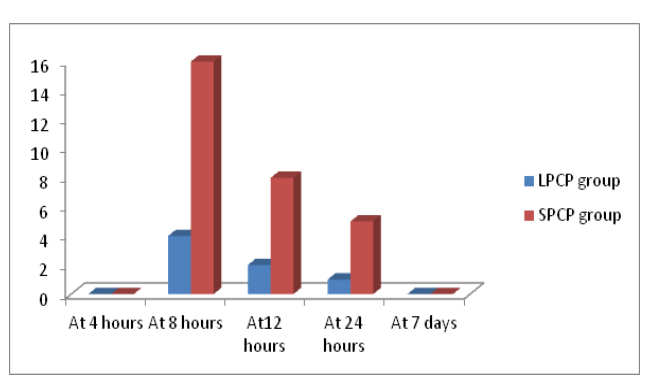

Figure 1: Frequency of Shoulder tip pain; LPCP: Low Pressure $\mathrm{CO}_{2}$ Pneumoperitoneum; SPCP: Standard Pressure $\mathrm{CO}_{2}$ Pneumoperitoneum

The mean shoulder pain VAS was significant in SPCP group at eight hoursand 12 hours while at four hours and 24 hours it 
was insignificant (Table II).

$\begin{array}{cccc}\begin{array}{c}\text { VAS Shoulder tip } \\ \text { pain score (mean) }\end{array} & \text { LPCP group } & \text { SPCP group } & \text { p value } \\ \text { At } 4 \text { hours } & 0.22 \pm 0.41 & 0.40 \pm 0.70 & 0.12 \\ \text { At } 8 \text { hours } & 0.44 \pm 1.10 & 2.88 \pm 2.73 & 0.006 \\ \text { At } 12 \text { hours } & 0.34 \pm 1.00 & 2.862 .64 & 0.008 \\ \text { At } 24 \text { hours } & 0.24 \pm 0.65 & 0.44 \pm 0.67 & 0.13 \\ \text { At 7 days } & 0 & 0 & -\end{array}$

Table II: Mean VAS shoulder tip pain score; VAS: Visual Analog Scale; LPCP: Low Pressure $\mathrm{CO}_{2}$ Pneumoperitoneum; SPCP: Standard Pressure $\mathrm{CO}_{2}$ Pneumoperitoneum

No patient in either group required top-up analgesia for shoulder pain at four hours and at seven days after surgery. Four (8\%) patients in LPCP group and $16(32 \%)$ in SPCP group required top up analgesia at 8 hours $(p=0.003)$. At 12 hours, eight (16\%) patients in SPCP group, while two $(4 \%)$ in LPCP group required top-up analgesia $(p=0.04)$. At 24 hours, five $(10 \%)$ patients in SPCP group, while one (2\%) in LPCP group required analgesia for shoulder pain $(p=0.09)$. following surgery (Figure 2).

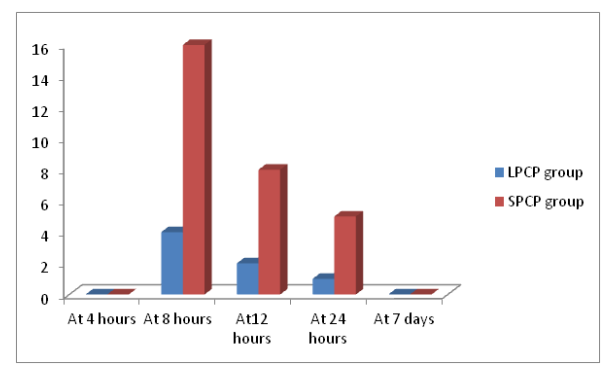

Figure 2:Frequency of Top-up analgesia requirement; LPCP: Low Pressure $\mathrm{CO}_{2}$ Pneumoperitoneum; SPCP: Standard Pressure $\mathrm{CO}_{2}$ Pneumoperitoneum

\section{DISCUSSION}

Although the pain occurring after laparoscopic surgery is less severe and of shorter duration than the open surgery, it still causes considerable discomfort and increases stress response in some patients. Sustained elevated intra-abdominal pressure for the duration of the procedure is associated with numerous undesirable consequences including postoperative shoulder tip pain ${ }^{6}$. Our study supports the fact that LC performed at LPCP $(8-10 \mathrm{mmHg})$ significantly reduces the incidence and severity of post-operative shoulder pain. Fourteen (28\%) patients in LPCP group and 32 (64\%) patients in SPCP had STP along with low mean severity of STP on VAS scale in LPCP group at four, eight 12 and 24 hours interval and was significant at eight hours $(p=0.006)$ and 12 hours $(p=0.008)$. This is consistent with study conducted by Goel et all where STP was significant at eight hours and 12 hours but insignificant at four hours and 24 hours and in another study conducted by Agarwal et al in 2021 , seven (14\%) in low pressure group versus $19(38 \%)$ in standard pressure group experienced STP with no significant difference in severity in one hour but significant difference in six $(p=0.002)$ and 12 hours $(p=0.002) .^{8,13}$ Bhatacharjee et al in 2016 and Alatrakchi et al in 2018 concluded that LPCP is a safe and effective alternative to SPCP with no increase in intraoperative complications, no significant conversion to high pressure and comparable surgeon's satisfaction score in both groups. Similarly we had no intraoperative complications in both groups, only one patient in LPCP group was converted to SPCP due to adhesion hindering the working space but was statistically insignificant and surgeon's satisfaction score was $4.66 \pm 065$ in LPCP group and $4.82 \pm 0.38$ in SPCP group ( $p$ $=0.14)^{2,12}$

In a study conducted by Ali et al, the mean intensity of pain on VAS in the LPCP group was $0.28 \pm 0.90$ whereas $1.31 \pm 2.38$ in SPCP $(p=0.001)$. Analgesic requirement was reduced significantly in LPLC and thus leading to early ambulation and better quality of life. The mean operative time was $27.84 \pm 6.078$ minutes in LPCP group and $28.51 \pm 7.45$ minutes in SPCP group. Similarly, Meena et al did a study in 2019 where they found mean VAS score at four hours in low pressure was $6.2 \pm 0.82$ and $6.8 \pm 0.98$ in standard pressure ( $p$ value $<0.001$ ). The need of analgesia in low pressure was $70 \mathrm{mg} / \mathrm{day}$ and standard pressure was $110 \mathrm{mg} /$ day $(p<0.001)$. Mean duration of surgery $46.2 \pm 2.80$ minutes in low pressure and mean duration of surgery $44.90 \pm 2.60$ minutes in standard pressure. In our study also, mean STP score was insignificant at four hours $(p=0.12)$ and 24 hours ( $p=0.13$ ) but significant $(p=0.006)$ at eight hours with $0.44 \pm 1.10$ and $2.88 \pm 2.73$ in LPCP and SPCP groups respectively. Likewise mean STP score was $0.34 \pm 1.00$ and $2.86 \pm 2.64$ in LPCP group and SPCP group respectively at 12 hours with $p$ value 0.008 . Four ( $8 \%$ ) patients in LPCP group and $16(32 \%)$ in SPCP group at 8 hours $(p=0.003)$, eight $(16 \%)$ patients in SPCP group, while two (4\%) in LPCP group $(p=0.04)$ required top-up analgesia. At 24 hours, five (10\%) patients in SPCP group, while one (2\%) in LPCP group required top-up analgesia for shoulder pain $(p=0.09)$. No patient required topup analgesia for shoulder pain at four hours and at seven days following surgery. This is also consistent with Kandil et al which showed STP started appearing after 2-6 h post-operatively, gradually increased in intensity up to about $12 \mathrm{~h}$, after which it started diminishing. Mean procedural time in our study was comparable and insignificant $(p=0.62)$ with $42.90 \pm 19.49$ and $40.98 \pm 19.35$ in LPCP and SPCP group respectively. ${ }^{3,14,15}$

Dey et al in 2013 observed more patients in the low pressure group had STP as compared with the high pressure group (20 versus seven) and was the most at 24 hours and gradually decreased thereafter in both the groups. Similarly Pulleet al in 2019 concluded in their study that reducing the pressure of the pneumoperitoneum to $8-10 \mathrm{mmHg}$ did not lower the incidence and intensity of postoperative STP, rather it could jeopardize the surgeon's comfort because of inadequate exposure and hence routine use of low-pressure pneumoperitoneum in LC was not recommended. Their contradictory findings were likely due to sustained elevated pneumoperitnoeum pressure because of longer operative time in low pressure. Conversely, our study showed decreased incidence and severity of STP in LPCP group at four, eight, 12 and 24 hours though it was statistically significant only at eight hours and 12 hours with no pain in any of the patients in both groups during follow up at seven days. In contrast to their study procedural time in our study was comparable in both groups. Although we observed higher surgeon's satisfaction score in LPCP group in terms of 
exposure and working space, it was insignificant and except one in LPCP group there was no conversion to high pressure and no intraoperative complications were seen in any group. ${ }^{16,17}$

In 2013 a meta-analysis was done by Huaet al in 1263 patients to know the feasibility and safety of low pressure pneumoperitoneum in LC. They found comparable operative time in low and high pressure group and LHS was shorter in the low-pressure group $(P=0.01)$. A RCT conducted by Joshipura et al in 2019 showed that though surgeons experienced more difficulty in dissection during low pressure pneumoperitoneum, it was significantly beneficial in terms of postoperative pain, use of analgesics, and hospital stay. In our study operating surgeon was not blinded about the pneumoperitoneum pressure during LC and thus this might have led to bias on assessing surgeon's satisfaction score $(p=0.14)$. Also, we found shorter LHS in LPCP group (1.02 \pm 0.14$)$ than SPCP group (1.20 $\pm 0.53)$ which was statistically significant $(p=0.02)$ possibly due to decreased incidence and severity of STP. ${ }^{4,18}$

\section{LIMITATIONS}

We did not include complicated gall stone diseases that might have required high pressure pneumoperitoneum for wide working space and safe dissection. The operating surgeon was not blinded for the pressure of pneumoperitoneum during the procedure and that may have led to bias on surgeon's satisfaction score. We did not asses STP between 24 hours and seven days and thus could not study the duration of shoulder pain in our study.

\section{CONCLUSION}

This study demonstrates that during LC in selected gall stone diseases, use of low pressure $\mathrm{CO}_{2}$ pneumoperitoneum is a safe and effective alternative to standard pressure $\mathrm{CO}_{2}$ pneumoperitoneum for significant reduction in frequency and intensity of post-operative shoulder tip pain without compromising working space.

\section{REFERENCES}

1. Schirmer BD, Edge SB, Dix J, Hyser MJ, Hanks JB, Jones RS. Laparoscopic cholecystectomy. Treatment of choice for symptomatic cholelithiasis. J Annals of surgery. 1991;213(6):665.

2. Bhattacharjee HK, Jalaludeen A, Bansal V, Krishna A, Kumar S, Subramanium $\mathrm{R}$, et al. Impact of standard-pressure and lowpressure pneumoperitoneum on shoulder pain following laparoscopic cholecystectomy: a randomised controlled trial. Surg Endosc. 2017;31(3):1287-95.

3. Meena J, Dawan ML, Dawan S. Low-Pressure Pneumoperitoneum Versus Standard Pneumoperitoneum in Laparoscopic Cholecystectomy: A Prospective Randomized Clinical Trial. NIJS. 2019;10(3):328-30.

4. Hua J, Gong J, Yao L, Zhou B, Song Z. Low-pressure versus standard-pressure pneumoperitoneum for laparoscopic cholecystectomy: a systematic review and meta-analysis. Am J Surg. 2014;208(1):143-50.
5. Sarli L, Costi R, Sansebastiano G, Trivelli M, Roncoroni $\mathrm{L}$. Prospective randomized trial of low-pressure pneumoperitoneum for reduction of shoulder-tip pain following laparoscopy. BJS. 2000;87(9):1161-5.

6. Donatsky AM, Bjerrum F, Gögenur I. Surgical techniques to minimize shoulder pain after laparoscopic cholecystectomy. A systematic review. Surg Endosc. 2013;27(7):2275-82.

7. Tsai H-W, Chen YJ, Ho CM, Hseu SS, Chao KC, Tsai SK, et al. Maneuvers to decrease laparoscopyinduced shoulder and upper abdominal pain: a randomized controlled study. Arch Surg. 2011;146(12):1360-6.

8. Goel A, Gupta S, Bhagat TS, Garg P. Comparative Analysis of Hemodynamic Changes and Shoulder Tip Pain Under Standard Pressure Versus Low-pressure Pneumoperitoneum in Laparo. Euroasian J of Hepatogastroenterol. 2019;9(1):5-8.

9. Barczynski M, Herman RM. A prospective randomized trial on comparison of low-pressure (LP) and standard-pressure (SP) pneumoperitoneum for laparoscopic cholecystectomy. Surg Endosc. 2003;17(4):533-8.

10. Couper MP, Tourangeau R, Conrad FG, Singer E. Evaluating the effectiveness of visual analog scales: A web experiment. Social Science Computer Review. 2006;24(2):227-45.

11. Joshi A, Kale S, Chandel S, Pal DK. Likert scale: Explored and explained. BJAST. 2015:396-403

12. Alatrakchi HA, Alchalabi FM, Alluwaizi KR. Prospective randomized comparison of low pressure versus standard pressure pneumoperitoneum in laparoscopic cholecystectomy. Ann Coll Med Mosul. 2018;40(1)41-5

13. Agarwal L, Kumawat S, Jain SA, Yadav A, Sharma S. Correlation of shoulder tip pain in case of low pressure and standard pressure pneumoperitoneum post laparoscopic cholecystectomy.Int Surg J. 2021;8(5)1522-5.

14. Ali IS, Shah MF, Faraz A, Khan M. Effect of intra-abdominal pressure on post-laparoscopic cholecystectomy shoulder tip pain: A randomized control trial. J Pak Med Assoc. 2016;66(10):45-9.

15. Kandil TS, Hefnawy EE. Shoulder pain following laparoscopic cholecystectomy: factors affecting the incidence and severity. J Laparoendosc Adv Surg Tech A. 2010;20(8):677-82.

16. Dey A, Malik VK. Shoulder Tip Pain Following Laparoscopic Cholecystectomy-a Randomized Control Study to Determine the Cause. Indian J Surg. 2015;77(2):381-4.

17. Pulle MV, Dey A, Mittal T, Mustafa T, Malik VK. Insufflation pressure and its effect on shoulder tip pain after laparoscopic cholecystectomy - A single-blinded, randomised study on 200 patients. Current Medicine Research and Practice. 2019;9(3):98-101.

18. Joshipura VP, Haribhakti SP, Patel NR, Naik RP, Soni HN, Patel $B$, et al. A prospective randomized, controlled study comparing low pressure versus high pressure pneumoperitoneum during laparoscopic cholecystectomy. Surg Laparosc Endosc Percutan Tech. 2009;19(3):234-40 